\title{
The Factors Enhance the Strength of Students' Computer Self-efficacy in a Computer Classroom
}

\author{
Yuwarat Srisupawong, Ravinder Koul, and Jariya Neanchaleay
}

\begin{abstract}
The success in computer courses is influenced by the levels of students' beliefs in their computer abilities (computer self-efficacy). Low level of computer self-efficacy (CSE) may affect to student's attention, engagement, and achievement in computer courses. Teacher feedback is one of the important factors helping students boost their CSE. The interaction with teachers influences students' intrinsic motivation and computer abilities. This study was to explore the influence of teachers' feedback in the computer classroom environment. The different types of teachers' feedback affect the different levels of students' CSE. An individual computer project was given to students. Data collection with pre-test and post-test design was used to capture students' changing perceptions of learning at the beginning and end of the computer course. The final sample was 105 high-school students in Thailand. A survey measured 8 items of abilities feedback, 5 items for general praise, 9 items for negative feedback, 5 items for CSE, and 24 items for SE Sources. Results from regression analysis revealed that SE source of social persuasions influenced by the ability feedback, along with general praise, and negative feedback respectively was the strongest predictor to predict students' CSE. The result highlighted not only teacher feedback can help students strengthen their CSE but also link with students' psychological needs in a computer classroom.
\end{abstract}

Index Terms-Computer classroom, computer self-efficacy, feedback, self-efficacy source.

\section{INTRODUCTION}

In Computer teaching and learning, students' self-efficacy belief (SE) has found to be associated with students' motivation, outcome expectations, and success in a computer program [1], [2]. Computer self-efficacy (CSE) plays an important role in students' perceptions of their abilities to accomplish computer tasks and perform successfully in work and learning environments [3], [4]. Students with low SE may difficult to succeed in the computer course [5], [6]. To promote CSE of students, the study of Ref. [7] recommended that teaching and training approaches of a computer course, feedback from teachers has been essential to boost students' CSE.

Manuscript received February 28, 2019; revised September 14, 2019.

Yuwarat Srisupawong is with Office of National Broadcasting and Telecommunications Commission, Thailand (e-mail: aea_kmutt@hotmail.com).

Ravinder Koul is with the Pennsylvania State University, USA. He is now with the Department of Curriculum and Instruction (e-mail: ramankoul@yahoo.com).

Jariya Neanchaleay is with King Mongkut's University of Technology Thonburi, Thailand. She is now with the Department of Educational Communications and Technology, Thailand (e-mail: Jariya.nea@kmutt.ac.th).
As the importance of CSE, the purpose of the study aimed to investigate the factors influencing the strength students' CSE. The results of the study do not only confirm the social cognitive theory of Ref. [8] but also link with students' psychological needs in a computer classroom.

\section{A. CSE}

CSE, a part of the social cognitive theory, is defined as the beliefs of judgments on students' capabilities of computer-related abilities and computer use in order to produce the amount of effort and the levels of performance or behaviors [3], [9]. CSE is derived from SE theory in general [8]. Prior studies of CSE resulted that high CSE influence students' higher level of confidence in their computer abilities [10], longer persistence in a computer program, higher prediction of learning outcomes [11]-[13].

\section{B. Social Cognitive Theory focusing on Feedback}

According to Ref. [8], the social cognitive theory of self-regulated learning emphasized that the interaction among personal, behavior and environmental influences helps students promote their learning practices and skills. SE plays an important role of self-regulation on student learning behavior and has a strong influence on student's effort and task persistence, especially in difficult circumstances [14], [15]. Ref. [16] examined the social cognitive model to understand the influences of a role of SE (personal), use of learning strategies, providing feedback (behavioral), and performance and receiving feedback (environmental) in the web-based learning environment (see Figure 1). They found that SE predicted students' use of learning strategies and influenced feedback behavior (personal $\Rightarrow$ behavioral). Receiving more feedback helped students promote their SE (environmental $=>$ personal).

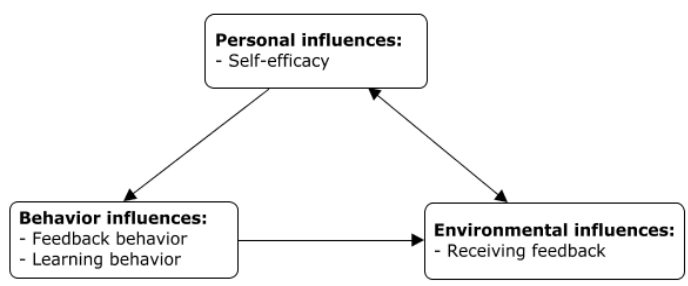

Fig. 1. The social cognitive model focusing on feedback [16].

\section{Types of Feedback}

\section{1) General praise}

Research on using praise in a classroom showed that effective praise from teachers can occur when they positively acknowledged on students' work [17]. Positive statement (praise) has been found to be more fruitful to students than 
verbal criticism [18]. Positive reinforcement with consistent praise is beneficial for encouraging desirable behavior, but extinguishing praise brings to undesirable behavior [19]. He also suggested that appropriate praise could be a tool for motivation on students' behavior. However, students' praise for trying hard is quite related to effort feedback than general praise [20].

\section{2) Ability feedback and negative feedback}

The perspective of social cognitive theory, feedback is an environmental variable influenced SE [21], [22]. Feedback is an environmental variable influenced by SE [21], [22]. Feedback mainly focused to ask students in the study are ability feedback and negative feedback. The example questions of ability feedback are "You have been working hard" and negative feedback is "Come on, you can do better" [23]. Ability feedback from teachers associated with students' interest in performing tasks [24]. Negative feedback from teachers impacts a negative relationship between students and teachers [23]. Students react to feedback in order to maintain their successful strategies and modify unsuccessful students [25]. Feedback helps students master on their learning strategies which are beneficial to maintain their learning success positively contributed to students' SE [26].

In a classroom, praise and feedback are the important methods which have been widely recommended for a teacher to use in class. These methods help a teacher build the students' view about themselves to be a good and valuable person [27], encourage students' capabilities to do their tasks, and build a close relationship between teachers and students [23]. Ref. [23] mentioned that teachers should have strategies which will give students praise and feedback. Not all students like to praise in public. In contrast, they want to praise quietly and personally in their ability and effort. Praise and feedback should be meet with students' preferences.

The study of Ref. [16] showed that social cognitive perspective has been significant toward a computer-based learning environment. This theory helps teachers promote students' motivation and facilitate students' learning behavior in a computer classroom [16]. As can be seen from the previous research, students' CSE is important for students' success in a computer learning domain [16]. Ref. [7] did a meta-analysis study, they recommended that teaching and training approaches of a computer course with behavior-modeling or feedback help a teacher promote students' CSE.

\section{SE Sources and Feedback}

Individual perceptions of SE depend on various personal interpretations from different sources of SE. SE sources generate positive experiences or feedback helped students promote their SE beliefs, in contrast with students who have negative experiences or feedback create low SE [28]. There are relationships among SE sources, feedback, and CSE [28]. Feedback acts as an important approach to promote high or low students' SE [28]. Four types of SE sources are the following:

First, mastery experiences relate to the success or failure from personal past performance. Second, vicarious experiences refer to create SE from observational experiences of significant persons e.g. peer, teachers, and adults. Third, social persuasions involve meaningful and encouraging feedbacks/judgments from influential persons. Last, physiological and affective states associated with emotional states such as anxiety, stress etc.) [29].

\section{E. Conceptual Framework}

Fig. 2 demonstrated the conceptual framework of the study. The study aimed to find the relationships among feedback, SE Sources, and CSE and the influence of factors toward the change-scored of CSE.

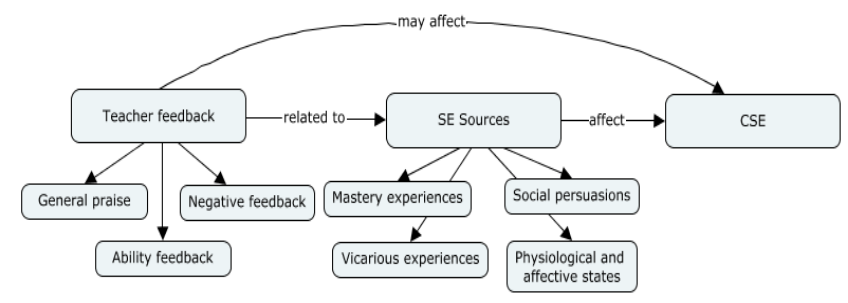

Fig. 2. Conceptual framework identifying the influence factors toward the change-scored of students' CSE.

\section{F. Research Questions}

1) What are the relationships among the changes-scores of types of feedback, SE Sources, and CSE?

2) What the change-score of feedback types (general praise, ability feedback, and negative feedback) is the strongest predictor for the change-score of SE Sources?

3) What the change-score of SE Sources (mastery experiences, social persuasions, physiological and affective states, and vicarious experiences) is the strongest predictor for the change-score of CSE beliefs?

\section{Methodology}

\section{A. Sample}

The study used the purposive sampling technique. Participants were 110 high-school students (Mathayom 6) from 3 classrooms who enrolled in web design and development course and completed pre-assessment. The final participants were 105 students (36.2\% males, $63.8 \%$ females) who completed post-assessment.

\section{B. Teachers' Feedback in Classrooms}

\section{1) Design}

Students of three computer classrooms were assigned to have feedback on each individual assignment. The sequence of instruction and all learning activities were delivered with the same condition for all classrooms.

\section{2) Teacher's feedback intervention}

A web design and development class had a 100-minute instructional session per week of a term project including lecture method, exercises, assignments, self-assessment, and pre- and post-assessments. When students finished each assignment, they would have self-assessment and teacher 
feedback.

\section{a) The first assignment}

Students had a take-home assignment which required students to finish before a next class began. The high-quality examples of work were demonstrated to students before they assessed themselves with the self-assessment. After that, a teacher assessed on students' work and gave individual feedback on their actual performance. Chances to learn from the high-quality example of work and teacher feedback may provide students to have an opportunity to learn and to improve their work as good as providing examples.

b) The second assignment

The second feedback would be used after students finished their website development. Four teaching sessions (400 minutes) were provided to students about how to create their own website including the system configuration setting, banner and template creation, and component setting etc. Students had a scoring rubric form to assess the performance and quality of their work. The example of a well-developed website and the reasons why this website was very good were expressed by the teacher. Individual feedback, for example, "Great Job! Only an image component would help you have a full function of an e-portfolio website" was delivered to all students. A teacher emphasized students to think and learn from the example and the suggestions. Students got an opportunity to learn how to develop a good website. They may feel more confidence in their ability when they can accomplish their work.

\section{c) The third assignment}

The third assignment required students' abilities to customize a computer program. Students had no prior experiences in computer programming. Thus, a teacher had to persuade students that they had enough abilities to deal with it. When all of the students had finished their tasks, they did self-assessment to assess the overall quality of work from the first to last assignments. Teacher's assessment and feedback convinced student's capability were delivered to students.

\section{Instrument}

Data collection relied on a survey having 3 parts as follows:

CSE scale was adopted from Ref. [30]. "I find working with computers very easy" and "I am very confident in my ability to use computers." are the examples of CSE scale. Cronbach's alpha value was .80 for pre-assessment and .84 for post-assessment.

Feedback scale consists of general praise, abilities feedback, and negative feedback which were adopted from Ref. [23]. There were five items for general praise, 8 items for abilities feedback, and 9 items for negative feedback. Cronbach's alpha value of teacher feedback in general praise, abilities feedback, and negative feedback for pre-assessment was respectively $.93, .93$, and .84 , and post-assessment was respectively $.85, .88$, and .88 .

The scale of SE Sources was adapted from Ref. [31]. Cronbach's alpha values of mastery experiences, vicarious experiences, social persuasions, and physiological and affective states were $.80, .86, .92$, and .91 for pre-assessment and $.80, .86, .92$, and .91 for post-assessment respectively.

This survey used a five-point Likert scale from 5 (Strongly agree) to 1 (Strongly disagree) for CSE and Feedback scales. A six-point Likert scale from 6 (Completely confident) to 1 (Not at all confident) used for SE Sources.

Instrument validity and reliability, the survey items were borrowed from the studies which were published and verified from the international journals. Cronbach's alpha of all constructs was higher than .70 which is indicated the adequate internal consistency reliability [32]. All survey items were written in Thai. The Translation-back-translation procedure (Two-way translations both English and Thai) was brought to ensure that all survey items were valid across cultures [33]. The survey was also pretested from 60 students.

\section{Data Collection and Analysis}

A survey of pre-assessment and post-assessment occurred at two stages. First, pre-assessment had been started before a course began. After a term's project, post-assessment had been collected the data from students. The differences in scores between pre- and post-assessments ("change scores") help researchers analysis students' progression on their CSE beliefs. The relationships among the change-scores of students in feedback, SE Sources, and CSE between pre- and post-assessment by using Pearson's correlation. Regression analyses would be used to find the change-scores of feedback types influenced the change-scores of social persuasion source and the change-scores of SE Sources also affected the change-scores of CSE beliefs.

\section{RESULT}

The result showed that the influential factors affect CSE after using feedback approach in a computer classroom. These results present a descriptive analysis, correlations, and linear regressions. Table I shows descriptive statistics and t-test results of students' perceptions of SE sources, feedback, and CSE from pre- and post-assessments, and the change-scores between pre- and post-assessments.

TABLE I: DESCRIPTIVE STATISTICS OF PRE-ASSESSMENT AND POST-ASSESSMENT AND T-TEST RESULTS OF THE CHANGE-SCORES

\begin{tabular}{|c|c|c|c|c|c|c|c|}
\hline \multirow[t]{2}{*}{ Variables } & \multicolumn{2}{|c|}{$\begin{array}{c}\text { Pre- } \\
\text { assessment }\end{array}$} & \multicolumn{2}{|c|}{$\begin{array}{c}\text { Post- } \\
\text { assessment }\end{array}$} & \multicolumn{3}{|c|}{ Change-scores } \\
\hline & $\mathrm{M}$ & SD & $M$ & SD & $M$ & SD & $t$ \\
\hline \begin{tabular}{|l|} 
Mastery \\
Experiences
\end{tabular} & 3.79 & .82 & 3.52 & .97 & $-.27 *$ & 1.08 & 2.51 \\
\hline \begin{tabular}{|l|} 
Vicarious \\
Experiences
\end{tabular} & 3.57 & 1.06 & 3.83 & .98 & $.26^{*}$ & 1.20 & -2.18 \\
\hline \begin{tabular}{|l|} 
Social \\
Persuasions \\
\end{tabular} & 2.66 & 1.11 & 3.03 & 1.08 & $.37 * *$ & .97 & -3.92 \\
\hline $\begin{array}{l}\text { Affective } \\
\text { states }\end{array}$ & 2.19 & 1.04 & 2.47 & 1.22 & $.28 *$ & 1.17 & -2.53 \\
\hline CSE & 3.00 & .67 & 3.16 & .71 & $.16^{*}$ & .64 & -2.46 \\
\hline $\begin{array}{l}\text { General } \\
\text { praise }\end{array}$ & 2.22 & 1.01 & 2.37 & .78 & .15 & 1.01 & -1.55 \\
\hline $\begin{array}{l}\text { Ability } \\
\text { feedback }\end{array}$ & 1.70 & .73 & 2.36 & .78 & $.66^{* * *}$ & .84 & -8.13 \\
\hline $\begin{array}{l}\text { Negative } \\
\text { feedback }\end{array}$ & 1.72 & .60 & 2.37 & .78 & $.65^{* *}$ & .75 & -9.00 \\
\hline
\end{tabular}


1) What are the relationships among the changes-scores of types of feedback, SE Sources, and CSE?

Pearson's correlation was given that there were significant relationships between all of the feedback types and social persuasions. Ability feedback had the highest correlation with social persuasions $(r=.505, \rho<0.01)$, along with teacher praise $(r=.489, \rho<0.01)$, and negative feedback $(r=.267$, $\rho<0.01)$. In addition, there was a relationship between the change-scores of social persuasions and CSE beliefs. Social persuasions had the highest correlation with CSE ( $r=.434$, $\rho<0.01$ ) while other variables did not have a significant relationship with CSE. These were given the results to support our first research question.

2) What the change-score of feedback types (general praise, ability feedback, and negative feedback) is the strongest predictor for the change-score of SE Sources?

Ability feedback was a strongest predictor to predict SE Sources: mastery experiences $(\beta=.546, \rho<0.001)$, vicarious experiences $(\beta=.426, \rho<0.001)$, and social persuasions $(\beta$ $=.478, \rho<0.001)$. However, no variables of feedback have significant to physiological and affective states.

Only the construct of social persuasions has statistical significant of all feedback types. Ability feedback stood out as the most important predictor to predict social persuasions, along with general praise, and negative feedback respectively. The standardized coefficient for ability feedback was significant $(\beta=.478, \rho<0.001)$, general praise $(\beta=.328$, $\rho<0.01)$, and negative feedback $(\beta=-.251, \rho<0.05)$. The set of predictors explained $34 \%$ of the variance in social persuasions. The result demonstrated in Table II.

TABLE II: ThE CHANGE-SCORES OF FEEDBACK TyPES PREDICTING THE

\begin{tabular}{|c|c|c|c|c|c|c|}
\hline & Variables & Construct & $\boldsymbol{\beta}$ & $t$ & $R^{2}$ & $\Delta R^{2}$ \\
\hline & Dependent & Mastery experiences & & & .226 & .203 \\
\hline & \multirow{3}{*}{ Independent } & General praise & -.009 & -.083 & & \\
\hline & & Ability feedback & .546 & $4.035^{* * * *}$ & & \\
\hline & & Negative feedback & -.098 & -.775 & & \\
\hline \multirow{4}{*}{2} & Dependent & Vicarious experiences & & & .125 & .099 \\
\hline & \multirow{3}{*}{ Independent } & General praise & -.056 & -.464 & & \\
\hline & & Ability feedback & .426 & $2.966 * *$ & & \\
\hline & & Negative feedback & -.062 & -.463 & & \\
\hline \multirow{4}{*}{3} & Dependent & Social persuasions & & & .335 & .315 \\
\hline & \multirow{3}{*}{ Independent } & General praise & .328 & $3.090 * *$ & & \\
\hline & & Ability feedback & .478 & $3.812^{* * * *}$ & & \\
\hline & & Negative feedback & -.251 & $-2.146^{*}$ & & \\
\hline \multirow{4}{*}{4} & Dependent & Affective states & & & .079 & .051 \\
\hline & \multirow{3}{*}{ Independent } & General praise & .129 & 1.035 & & \\
\hline & & Ability feedback & .048 & .326 & & \\
\hline & & Negative feedback & .146 & 1.058 & & \\
\hline
\end{tabular}

3) What the change-score of SE sources (mastery experiences, social persuasions, physiological and affective states, and vicarious experiences) is the strongest predictor for the change-score of CSE beliefs? The result from regression analysis revealed students' perceptions of SE Sources as predictors of CSE. Within a set of SE Sources, social persuasion source was a positively significant predictor $(\beta=.528, \rho<0.001)$ while other SE Sources did not show significance in this table as showing in Table III. The amount of variance explained $22 \%$ predicting CSE.

TABLE III: THE CHANGE-SCORES OF SE SOURCES PREDICTING THE CHANGE-SCORE OF STUDENTS' CSE BELIEFS $(N=105)$

\begin{tabular}{|c|c|c|c|c|c|}
\hline \multicolumn{6}{|c|}{$N=105)$} \\
\hline Variables & Construct & $\beta$ & $t$ & $R^{2}$ & $\Delta R^{2}$ \\
\hline Dependent & CSE & & & .218 & .186 \\
\hline \multirow{4}{*}{ Independent } & Mastery Experiences & -.100 & -.985 & & \\
\hline & Vicarious Experiences & .016 & .163 & & \\
\hline & Social Persuasions & .528 & $4.912 * *$ & & \\
\hline & $\begin{array}{l}\text { Physiological and } \\
\text { affective states }\end{array}$ & -.151 & -1.558 & & \\
\hline
\end{tabular}

A computer course with feedback helped students develop their CSE beliefs. The scores from post-assessment had been increased from pre-assessment after the intervention method had been implemented. The results give evidence to support all research questions.

In sum, the change in ability feedback was the strongest predictor influencing the change in social persuasions, along with general praise, and negative feedback respectively. Only negative feedback was found to be a negative effect on the change in social persuasions. The results are consistent with Ref. [23] concluded that students will satisfy when they receive ability feedback and less negative feedback. Ability feedback helps students increase their competency and academic abilities [34]. The receiving comments motivate students to try harder [20]. However, general praise is quite related to more general tasks and less related to students' abilities than ability feedback [23]. Over-exaggerations of praise or feedback do not help students strengthen their CSE [35].

The change-score of social persuasion source was found to be significant to the change-score of students' CSE beliefs but other SE sources did not show significance to predict the change-scored of students' CSE. Ref. [29] and Ref. [36] mentioned that social persuasions are very beneficial when students encounter with new skills, difficult tasks, or lack of mastery experiences. Social persuasions (e.g., feedback) help students develop and strengthen their CSE [29]. The current study highlighted that social persuasions with feedback approach need in a computer classroom. The result is consistent with the prior study that the strength of social persuasions depend on the significant others providing evaluative feedback, judgment, or appraisal on students' performance [31]. The trust of significant people can help students boost their confidence in academic abilities.

\section{CONFLICT OF INTEREST}

The authors declare no conflict of interest. 


\section{AUTHOR CONTRIBUTIONS}

Srisupawong Y., Koul R., and Neanchaleay J. conducted the research; Srisupawong Y. and Koul R. analyzed the data; Srisupawong Y. wrote the paper; all authors had approved the final version.

\section{REFERENCES}

[1] D. Compeau, C. Higgins, and S. Huff, "Social cognitive theory and individual reactions to computing technology: A longitudinal study," MIS Quarterly, pp. 145-158, 1999.

[2] M. Igbaria and J. Iivari, "The effects of self-efficacy on computer usage," Omega, vol. 23, no. 6, pp. 587-605, 1995.

[3] D. Compeau and C. Higgins, "Computer self-efficacy: Development of a measure and initial test," MIS Quarterly, vol. 19, no. 2, pp. 189-211, doi: $10.2307 / 249688,1995$.

[4] H. Sam, A. Othman, and Z. Nordin, "Computer self-efficacy, computer anxiety, and attitudes toward the internet: A study among undergraduates in Unimas," Journal of Educational Technology \& Society, vol. 8, no. 4, pp. 205-219, 2005.

[5] T. Beaubouef and P. McDowell, "Computer science: Student myths and misconceptions," Journal of Computing Sciences in Colleges, vol. 23, no. 6, pp. 43-48, 2008.

[6] R. Vivian, K. Falkner, and N. Falkner, "Computer science students' causal attributions for successful and unsuccessful outcomes in programming assignments," in Proc. the 13th Koli Calling International Conference on Computing Education Research, Koli, Finland: ACM, 2013, pp. 125-134.

[7] D. Moos and R. Azevedo, "Learning with computer-based learning environments: A literature review of computer self-efficacy," Review of Educational Research, vol. 79, no. 2, pp. 576-600, doi:10.3102/0034654308326083, 2009.

[8] A. Bandura, Social Foundations of Thought and Action: A Social Cognitive Theory, Englewood Cliffs, NJ: Prentice-Hall, Inc., 1986.

[9] A. Bandura, "Self-efficacy: Toward a unifying theory of behavioral change," Psychological Review, vol. 84, no. 2, pp. 191-215, doi:10.1037/0033-295x.84.2.191, 1977.

[10] O. Akinbobola and A. Adeleke, "The influence of user efficacy and expectation on actual system use," Interdisciplinary Journal of Information, Knowledge, and Management, vol. 8, pp. 43-57, 2013.

[11] B. Hasan, "The influence of specific computer experiences on computer self-efficacy beliefs,"Computers in Human Behavior, vol. 19, no. 4, pp. 443-450, doi:10.1016/s0747-5632(02)00079-1, 2003.

[12] P. Kinnunen and B. Simon, "CS majors' self-efficacy perceptions in CS1: Results in light of social cognitive theory," in Proc. the Seventh International Workshop on Computing Education Research, Providence, RI: ACM, 2011, pp. 19-26.

[13] C. Marsh, "A sub-saharan comparative study of university students' attitudes towards computer programming," in Proc. the Fifteenth Annual Conference on Innovation and Technology in Computer Science Education, Ankara, Turkey: ACM, 2010, pp. 33-37.

[14] P. Pintrich and D. Schunk, Motivation in Education: Theory, Research, and Applications (2nd ed.), Englewood Cliffs, NJ: Prentice Hall, 2002.

[15] D. Schunk, "Self-efficacy and education and instruction," Self-efficacy, Adaptation, and Adjustment: Theory, Research, and Application, Boston, MA: Springer, 1995, pp. 281-303.

[16] S. Wang and P. Wu, "The role of feedback and self-efficacy on web-based learning: The social cognitive perspective," Computers \& Education, vol. 51, no. 4, pp. 1589-1598, doi:10.1016/j.compedu.2008.03.004, 2008.

[17] R. Hitz and A. Driscoll, "Praise or encouragement? New insights into praise: Implications for early childhood teachers," Young Children, vol. 43, no. 5, pp. 6-13, 1989.

[18] P. Burnett, "Children's self-talk and academic self-concepts: The impact of teachers'statements," Educational Psychology in Practice, vol. 15, pp 195-200, doi:10.1080/0266736990150308, 1999.

[19] J. Thomas, "You're the greatest! A few well-chosen words can work wonders in positive behavior reinforcement," Principal, vol. 71, pp. 32-33, 1991.

[20] P. Burnett and V. Mandel, "Praise and feedback in the primary classroom: Teachers' and students' perspectives," Australian Journal of Educational \& Developmental Psychology, vol. 10, pp. 145-154, 2010.
[21] D. Schunk, "Self-efficacy for reading and writing: Influence of modeling, goal setting, and self-evaluation," Reading and Writing Quarterly, vol. 19, no. 2, pp. 159-172, doi:10.1080/10573560308219, 2003.

[22] D. Schunk and B. Zimmerman, "Social origins of self-regulatory competence," Educational Psychologist, vol. 32, no. 4, pp. 195-208, doi:10.1207/s15326985ep3204_1, 1997.

[23] P. Burnett, "Teacher praise and feedback and students' perceptions of the classroom environment," Educational Psychology, vol. 22, no. 1, pp. 5-16, doi:10.1080/01443410120101215, 2002.

[24] C. Mueller and C. Dweck, "Praise for intelligence can undermine children's motivation and performance," Journal of Personality and Social Psychology, vol. 75, no. 1, pp. 33-52, doi:10.1037/0022-3514.75.1.33, 1998 .

[25] B. Zimmerman, "Becoming a self-regulated writer: A social cognitive perspective," Contemporary Educational Psychology, vol. 22, pp. 73-101, doi:10.1006/ceps.1997.0919, 1997.

[26] J. Chan and S. Lam, "Effects of different evaluative feedback on students' self-efficacy in learning," Instructional Science, vol. 38, no. 1, pp. 37-58, doi:10.1007/s11251-008-9077-2, 2010.

[27] H. Kernis, "Toward a conceptualization of optimal self-esteem," Psychological Inquiry, vol. 14, no. 1, pp. 1-26, doi:10.1207/S15327965PLI1401_01, 2003.

[28] N. Akkuzu, "The role of different types of feedback in the reciprocal interaction of teaching performance and self-efficacy belief," Australian Journal of Teacher Education, vol. 39, pp. 37-66, 2014.

[29] S. Britner and F. Pajares, "Sources of science self-efficacy beliefs of middle school students," Journal of Research in Science Teaching, vol. 43, no. 5, pp. 485-499, doi:10.1002/tea.20131, 2006.

[30] M. Papastergiou, "Are computer science and information technology still masculine fields? High school students' perceptions and career choices," Computers \& Education, vol. 51, no. 2, pp. 594-608, doi:10.1016/j.compedu.2007.06.009, 2008.

[31] E. Usher and F. Pajares, "Sources of self-efficacy in mathematics: A validation study," Contemporary Educational Psychology, vol. 34, no. 1, pp. 89-101, doi:10.1016/j.cedpsych.2008.09.002, 2009.

[32] D. George and P. Mallery, SPSS for Windows Step by Step: A Simple Guide and Reference 14.0 Update (7th ed.), Needham Heights, MA: Allyn \& Bacon, 2003.

[33] R. Brislin, "Translation and content analysis of oral and written material," Handbook of Cross-cultural Psychology, Boston, MA: Allyn \& Bacon, 1980, pp. 389-444.

[34] D. Schunk, "Self-efficacy and academic motivation," Educational Psychologist, vol. 26, no. 3-4, pp. 207-231, doi:10.1080/00461520.1991.9653133, 1991.

[35] M. Dinther, F. Dochy, and M. Segers, "Factors affecting students' self-efficacy in higher education," Educational Research Review, vol. 6 , no. 2, pp. 95-108, doi:10.1016/j.edurev.2010.10.003, 2011.

[36] J. Tzeng, "The impact of general and specific performance and self-efficacy on learning with computer-based concept mapping," Computers in Human Behavior, vol. 25, no. 4, pp. 989-996, doi:10.1016/j.chb.2009.04.009, 2009.

Copyright $@ 2019$ by the authors. This is an open access article distributed under the Creative Commons Attribution License which permits unrestricted use, distribution, and reproduction in any medium, provided the original work is properly cited (CC BY 4.0).

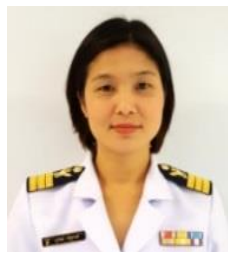

Yuwarat Srisupawong received a doctoral degree in learning innovation and technology from King Mongkut's University of Technology Thonburi, Thailand. She is working at Office of National Broadcasting and Telecommunications Commission of Thailand. Her research involves computer self-efficacy of computer students.

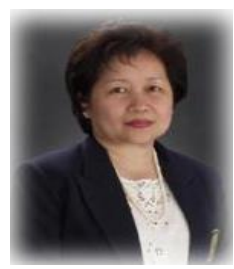

Jariya Neanchaleay is a lecturer and adviser at King Mongkut's University of Technology Thonburi, Thailand. Her research related to teaching and learning in the area of education technology. 